\title{
Entre châtaigner et palmier chonta. Hommage à Juan Bottasso (1936-2019)
}

Geoffroy de Saulieu, Stéphen Rostain, Anne-Christine Taylor et Philippe Descola

\section{(2) OpenEdition}

\section{Journals}

Édition électronique

URL : https://journals.openedition.org/jsa/18178

DOI : $10.4000 /$ jsa. 18178

ISSN : 1957-7842

Éditeur

Société des américanistes

\section{Édition imprimée}

Date de publication : 30 juin 2020

Pagination : 223-228

ISBN : 978-2-902715-13-8

ISSN : 0037-9174

Référence électronique

Geoffroy de Saulieu, Stéphen Rostain, Anne-Christine Taylor et Philippe Descola, « Entre châtaigner et palmier chonta. Hommage à Juan Bottasso (1936-2019) », Journal de la Société des américanistes [En ligne], 106-1 | 2020, mis en ligne le 30 juin 2020, consulté le 28 septembre 2022. URL : http:// journals.openedition.org/jsa/18178; DOI : https://doi.org/10.4000/jsa.18178 


\section{Entre châtaigner et palmier chonta. Hommage à Juan Bottasso (1936-2019)}

Geoffroy de Saulieu, Stéphen Rostain, Anne-Christine TAYlor et Philippe Descola

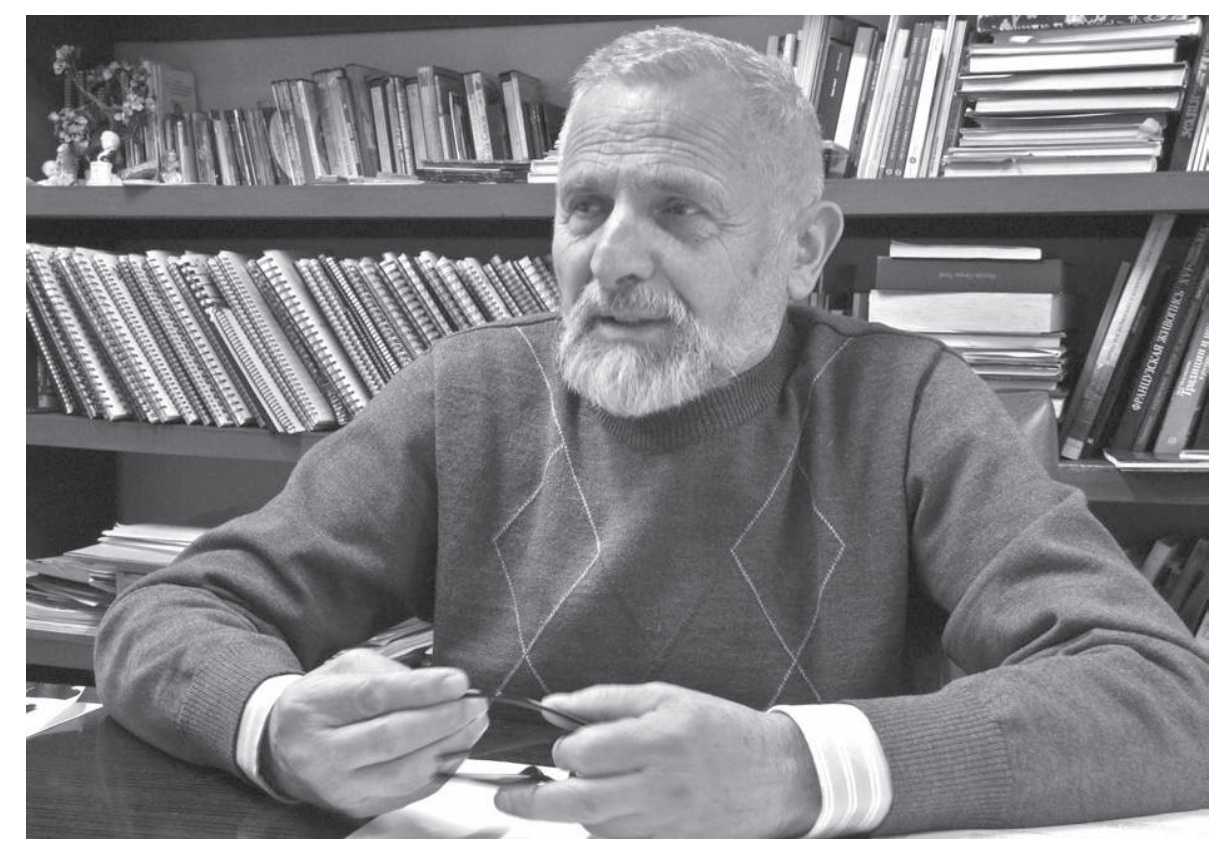

Fig. 1 - Juan Bottasso dans son bureau de Quito, dans le musée et la librairie d'Abya-Yala, où il passait le plus clair de son temps à lire des manuscrits (avec l'aimable autorisation des Éditions Abya-Yala).

* G. De Saulieu: IRD, UMR 208 Paloc, Paris [geoffroy.desaulieu@ird.fr]; S. Rostain : CNRS, UMR 8096 ArchAm, MSH Mondes, Nanterre [stephen.rostain@cnrs.fr]; A.-C. TAYLOR: Directrice de recherche émérite au CNRS [anchumir@gmail.com]; P. Descola: Professeur émérite au Collège de France [descola@ehess.fr]. 
« Ce [...] devrait être l'occasion d'adresser une invitation solennelle à tous les groupes chrétiens à cesser de diviser les peuples amazoniens. »

(Juan Bottasso, « Lettre ouverte », 2019)

Juan Bottasso, père salésien, équatorien d'origine italienne, est mort le 24 décembre 2019. Figure connue et respectée dans tout le pays, il était un témoin et un acteur-clé de l'histoire équatorienne depuis un demi-siècle. Il est surtout pleuré dans l'Oriente, la partie amazonienne du pays, tant sa vie a marqué celle de cette région et de ses habitants, tout particulièrement celle du peuple shuar, qui comparait Bottasso à un grand arbre. Il en avait la résistance, la droiture, la capacité à porter ombrage - sa hiérarchie ecclésiastique en savait quelque chose -, mais aussi d'abriter et de conforter tous ceux cherchant refuge. Il en avait aussi la prestance, avec un admirable visage et un port de tête évoquant l'imagerie du condottiere. Brûlant, enthousiaste mais loin d'être naïf, caustique sans méchanceté, le regard un peu piquant parfois, Juan Bottasso tenait autant du buisson d'épines que du chêne. Né dans les forêts de châtaigniers piémontaises, il avait choisi le déracinement pour partir chez les Salésiens en Amérique latine avec tant d'autres compatriotes de son époque.

Après des études de théologie en Colombie et son ordination en 1963, il rejoignit la maison salésienne d'Équateur et resta huit ans dans les missions de Méndez et de Gualaquiza, dans la province amazonienne de Morona-Santiago, alors que le pays connaissait de tristes épisodes de dictatures militaires (19631966 et 1972-1978). Ses convictions à gauche et son statut de prêtre étranger concentraient sur lui des soupçons de fomenter la révolution. De pensée libre, il considérait toujours « qu'il vaut mieux demander pardon que de demander l'autorisation ». Plutôt que de le renvoyer à Rome, comme ce fut le cas pour d'autres, ses supérieurs le placèrent de 1971 à 1974 à l'université pontificale catholique d'Équateur à Quito pour y enseigner la théologie.

En 1975, il parvint à revenir dans ses terres d'adoption en Amazonie, parmi les populations shuar, en tant que vicaire apostolique. Ces Amérindiens, on le sait, traînaient encore à l'époque une fâcheuse réputation de férocité sanguinaire et d'insolence à l'égard des autorités tant civiles que religieuses. Considérés comme « la mission la plus difficile du monde », ils opposaient à l'entreprise d'évangélisation tantôt une indifférence exaspérante tantôt une fâcheuse disposition à argumenter pied à pied avec les religieux. Sans doute est-ce ce mélange d'indépendance sourcilleuse, de liberté de penser et de goût pour l'ironie qui attacha si fortement Bottasso aux Shuar, au point de mêler sa destinée à la leur. Avec un groupe de Salésiens inspirés comme lui par la

1. www.infoans.org/es/secciones/noticias/item/8946-vaticano-carta-abierta-a-los-padressinodales-del-padre-juan-botasso, consulté le 15/06/20. 


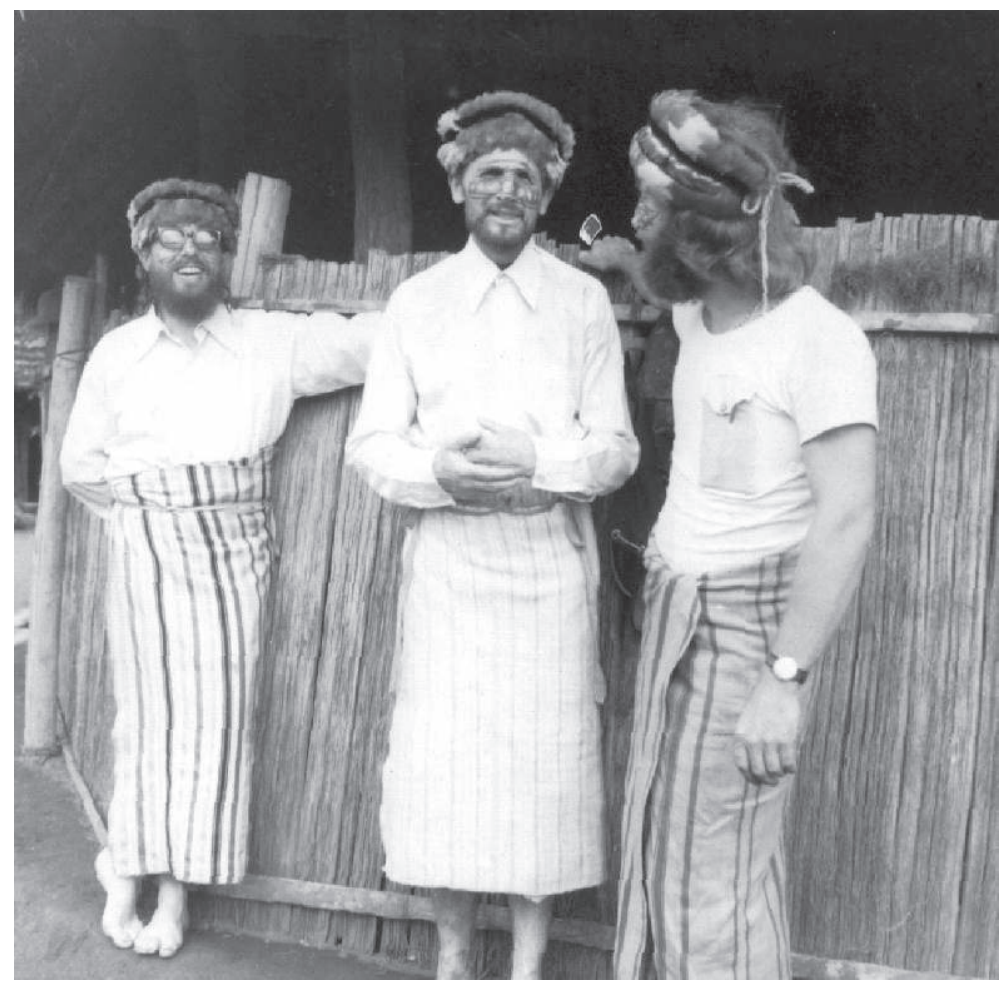

Fig. 2 - En partie vêtu à la Shuar, Juan Bottasso (au centre) avec ses amis Yankuam et José Arnalot, dans les années 1970, en Amazonie équatorienne (avec l'aimable autorisation des Éditions Abya-Yala).

théologie de l'incarnation issue de Vatican II, et proche de la théologie de la libération, il prit le risque de mettre sur pied la Fédération Shuar, le premier mouvement indigène organisé dans le monde amazonien. Il rassembla autour de cette institution - devenue entretemps indépendante des missionnaires et formant aujourd'hui une composante centrale du puissant mouvement indigène en Équateur - un groupe de jeunes volontaires, italiens pour la plupart, dont plusieurs partagèrent longuement la vie des Shuar en laissant de précieux et souvent émouvants mémoires de ces années.

Pour la petite histoire de l'archéologie, c'est durant cette période qu'il emmena son confrère joséphite ${ }^{2}$ Pedro Porras sur le site archéologique de Sangay. Ce moment l'avait marqué et il aimait se le remémorer: Porras débarque un matin dans le petit aérodrome de Macas et voit arriver Bottasso dans sa vieille auto bringuebalante. Ce dernier lui propose de profiter de cette journée

2. De la congrégation de saint Joseph. 
ensoleillée pour aller visiter le site archéologique qu'il avait découvert à une vingtaine de kilomètres au nord, en bordure du ravin de l'Upano. Ce sont des dizaines de gros monticules artificiels de terre rectangulaires disposés de façon géométrique autour de places basses et connectés par de larges chemins creusés. Ces complexes interconnectés constituent les vestiges d'une énorme agglomération précolombienne oubliée. Le trajet cahotant des visiteurs les conduit un peu en hauteur d'où ils ont une vue imprenable, les tertres se détachant superbement grâce au soleil rasant de fin d'après-midi. Quelques années plus tard, Porras y mènera des fouilles archéologiques et publiera un gros livre, en oubliant pieusement de mentionner le véritable découvreur du site.

Cependant, la profonde ardeur de Bottasso n'était pas l'archéologie, plutôt le monde amérindien contemporain. Sur la lancée du projet de fédération indigène, il démarra à Macas, en 1975, la production d'une série de livrets sur le monde shuar, en s'appuyant sur les écrits tant de ses frères missionnaires que des volontaires laïques. Mundo Shuar allait constituer une véritable encyclopédie réunissant différentes sources concernant la culture des Shuar, en 78 tomes parus de 1975 à 1983. La série reste une référence incontournable pour quiconque s'intéresse aux Chicham Aents - pour donner aux groupes jivarophones la dénomination qu'ils se sont récemment choisie, jugeant offensant l'usage du terme Jivaro.

Renvoyé à Quito en 1979 pour raisons politiques, on l'exila en 1980 à Cayambe, dans un collège technique salésien. Il profita des équipements du collège et de l'enthousiasme des élèves pour lancer une autre série, Mundo andino, avant de fonder en 1983 les éditions Abya-Yala, reprenant un terme kuna signifiant « notre terre ». En effet, à cette époque, un mouvement autochtone continental propose que tous les peuples indigènes des Amériques nomment ainsi leurs terres d'origine. Les premières années, la diffusion de leurs livres, tant en Équateur qu'ailleurs en Amérique latine, reposait surtout sur les voyages effectués par des bonnes sœurs volontaires ou des religieux amis de Bottasso; aujourd'hui, avec près de 20000 titres publiés, Abya-Yala est l'une des principales maisons d'édition d'Équateur, voire d'Amérique latine, spécialisée en anthropologie, en sociologie, en linguistique, en histoire et en écologie.

En 1991, il renta à Quito pour se consacrer à Abya-Yala et entreprit de créer un musée de l'Amazonie - initiative marquante, à valeur symbolique, car nul ne songeait à l'époque à inclure le monde de l'Oriente dans le patrimoine culturel de l'Équateur. À partir de 1992, Bottasso rassembla donc les pièces archéologiques et ethnographiques rapportées par les salésiens depuis des décennies afin de fonder le musée d'Abya-Yala, l'une des références de la capitale équatorienne. Le siège d'Abya-Yala se convertit rapidement en un lieu de passage obligé pour tous les chercheurs tant nationaux qu'étrangers, toujours accueillis avec intérêt et bienveillance par Bottasso ou par José Juncosa, nommé responsable des éditions il y a quelques années. 
Juan Bottasso devint en 1994 le doyen de la Faculté des sciences humaines et sociales de l'université polytechnique salésienne de Quito (Universidad Politécnica Salesiana, UPS) où, toujours soucieux de marier le savoir à l'action, il avait auparavant fondé l'Institut d'anthropologie appliquée. En plus de l'enseignement et de la formation, il s'intéressa beaucoup au dialogue entre l'institution ecclésiale et les populations amérindiennes, réflexion qu'il ne détachait pas d'une démarche imprégnée d'autocritique, intégrant les questions plus larges de la culture et de la pauvreté dans la société contemporaine, comme en témoigne, par exemple, la revue Iglesia, Pueblo y Cultura qu'il a longtemps dirigée. Il a également réuni et édité une importante compilation, en plusieurs volumes, de documents sur l'histoire des missions salésiennes et leurs relations avec les Shuar - n'hésitant pas à y inclure des écrits et des photos témoignant d'un passé que d'aucuns préféreraient oublier, qu'il s'agisse de la période fasciste en Italie ou de la sombre époque des internats pour enfants indigènes.

Toutes les œuvres de Juan Bottasso témoignent de son charisme, de son énergie hors du commun et son immense générosité. Elles attestent surtout sa volonté tenace de forger des institutions capables de réellement agir sur le monde. Inflexible sur les principes mais pragmatique sur la méthode, il réussissait, par son charme et son intelligence, à négocier les méandres de la vie politique locale comme celles de la nonciature.

Dans une lettre ouverte envoyée peu avant son décès aux religieux réunis pour un synode au Vatican, il formula le vœu « que l'Église amazonienne prenne conscience et s'excuse humblement pour le manque de respect par le passé des valeurs culturelles des peuples autochtones ». Cet ultime courrier n'est sans doute pas resté lettre morte, à en juger par les récentes prises de position du pape à l'hiver 2020 .

Juan Bottasso avait eu la douleur de voir disparaître peu à peu presque tous ses compagnons missionnaires en Amazonie : son frère Domingo Bottasso et Luis Bolla, incomparables connaisseurs de la culture et de l'histoire des Achuar; Alfredo Germani (Aijiu Juank), fasciné par la langue shuar et la maîtrisant sans doute mieux que la plupart des jeunes Amérindiens; Siro Pellizzarro, l'infatigable compilateur et traducteur des mythes et des énoncés rituels shuar; Lino Rampón, le premier à avoir rassemblé les objets constituant aujourd'hui la collection du musée. Avec sa mort, survenue quelques mois après celle de Ricardo Tankamash, l'un des leaders historiques de la Fédération Shuar, disparaît ainsi toute une génération d'hommes dévoués corps et âmes à défendre et à documenter la culture shuar.

Remerciements - Aux Éditions Abya-Yala et leur directrice Milagros Aguirre pour leurs documents. 
G. de Saulieu, S. Rostain, A.-C. Taylor et P. Descola

\section{À lire}

Aguirre Milagros A. et María Susana Cipolletti (dir.)

2020 Sin esperanza no hay alegría. En Memoria de Juan Bottasso, sdb (1936-2019), Ediciones Abya-Yala, Quito. 